\title{
Lithium Ion Battery Separators Based On Carboxylated Cellulose Nanofibers From Wood
}

Hyeyun Kim, ${ }^{*}, \dagger, \ddagger, \S \odot$ Valentina Guccini, ${ }^{\dagger, \|}$ Huiran Lu, ${ }^{\S, \mathbb{I}}$ Germán Salazar-Alvarez, ${ }^{\dagger, \|}$ Göran Lindbergh, ${ }^{\dagger, \S}$ and Ann Cornell ${ }^{\dagger, \S(0)}$

\author{
${ }^{\dagger}$ Wallenberg Wood Science Centre, Royal Institute of Technology, KTH Royal Institute of Technology, SE100 44 Stockholm, \\ Sweden \\ ${ }^{\ddagger}$ Department of Fibre and Polymer Technology, KTH Royal Institute of Technology, SE100 44 Stockholm, Sweden \\ ${ }^{\S}$ Department of Chemical Engineering, KTH Royal Institute of Technology, SE100 44 Stockholm, Sweden \\ "Department of Materials and Environmental Chemistry, Stockholm University, SE106 91 Stockholm, Sweden
}

Supporting Information

ABSTRACT: Carboxylated cellulose nanofibers, prepared by TEMPO-mediated oxidation (TOCN), were processed into asymmetric mesoporous membranes using a facile papermaking approach and investigated as lithium ion battery separators. Membranes made of TOCN with sodium carboxylate groups (TOCN-COO${ }^{-} \mathrm{Na}^{+}$) showed capacity fading after a few cycles of charging and discharging. On the other hand, its protonated counterpart (TOCN-COOH) showed highly improved electrochemical and cycling stability, displaying $94.5 \%$ of discharge capacity maintained after 100 cycles at $1 \mathrm{C}$ rate of charging and discharging. The
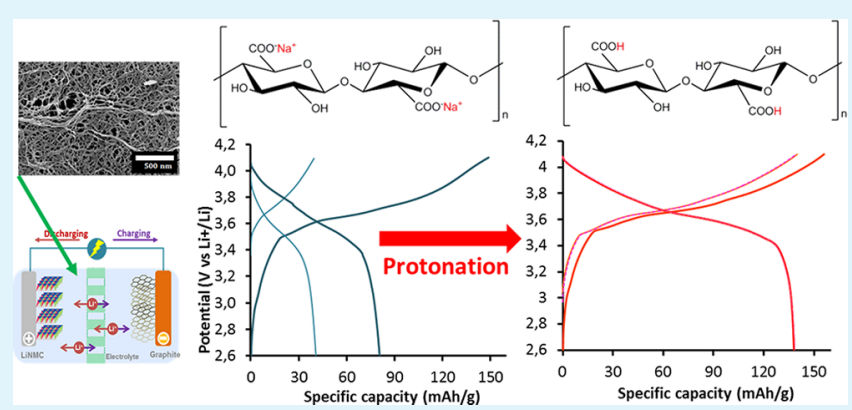
asymmetric surface porosity of the membranes must be considered when assembling a battery cell as it influences the rate capabilities of the battery. The wood-based TOCN-membranes have a good potential as an ecofriendly alternative to conventional fossil fuel-derived separators without adverse side effects.

KEYWORDS: cellulose, Li-ion batteries, separator, TEMPO-oxidized cellulose, protonation

\section{INTRODUCTION}

One of the key concerns of the lithium ion battery industry is its large environmental impact, especially in terms of high energy input during the manufacturing and the lack of recycling of the components. ${ }^{1,2}$ Consequently, there have been numerous attempts to replace the components of lithium ion batteries to degradable and renewable materials, such as biopolymers. ${ }^{3,4}$ Particularly, cellulose has been highlighted as an alternative material to petroleum based polymers due to its abundance, low costs, and low environmental impact.

Using cellulose pulp as raw material, it is possible to obtain valuable forms of nanoparticles with enhanced mechanical, optical, and functional properties. ${ }^{5}$ Among the nanoparticles, cellulose nanofibers (CNF) refer to cellulose nano-objects, with two similar external dimensions in the nanoscales and a significantly larger third dimension. The term "cellulose nanofibers" can, therefore, be used to encompass its synonyms including microfibrillated cellulose and cellulose microfibrils. Cellulose nanofibrils are a type of cellulose nanofibers with nanoscale dimensions of 5-30 $\mathrm{nm}$ and an aspect ratio higher than $50.6,7$

Accordingly, CNF has highly enhanced dispersibility in various solvents, which can be processed into nanostructured porous materials. It widens the spectrum of its application, for example, electrochemical energy storage devices including rechargeable battery materials. ${ }^{8-16}$ Combined with its inherent superior thermal stability (melting point $\geq 250{ }^{\circ} \mathrm{C}$ ), $\mathrm{CNF}$ can be taken account into a promising separator material, to overcome the drawbacks of commercial polyolefin separator materials (melting point $\approx 125{ }^{\circ} \mathrm{C}$ ) and the safety issues. $^{11-13,15,17-21}$ Chun et al. produced lithium ion battery separators made of $\mathrm{CNF}$, which were mechanically treated and dispersed in isopropanol and fabricated to mesoporous membranes by a vacuum filtration method. ${ }^{12}$ Wang et al. reported a cellulose-based functional separator with a redoxactive polypyrrole layer by the vacuum filtration method. ${ }^{22}$

Chemically modified cellulose has also been investigated as separator or gel polymer electrolyte materials. ${ }^{13,23-25}$ Chemical modification is required to facilitate mechanical disintegration of cellulose fibers to nanofibers. ${ }^{26}$ In many cases, negatively charged groups are introduced on the cellulose surface, which form strong electrostatic repulsion between fibrils. Such polyanionic materials can be promising for separators or gel polymer electrolyte in lithium ion batteries, since negative

Received: October 19, 2018

Accepted: December 28, 2018

Published: December 28, 2018 
surface charges can contribute to efficient transport of lithium ions because of their hydrophilicity and the interaction between hydroxyl groups and carbonated-based electrolyte solvents. $^{24,25,27-29}$ For instance, carboxymethyl cellulose (CMC) dispersed in N,N-dimethylformamide (DMF) was used as a polymer gel electrolyte (PGE) and demonstrated good electrochemical performance with high stability. ${ }^{27}$ It was suggested that carboxylate groups effectively facilitate the transport of lithium ions, and also showed the electrochemical stability of CMC. Apart from cellulose materials, separators made of carboxylated polyolefin or polyimide also reported greatly enhanced electrochemical performance, when turning hydrophobic materials into partially hydrophilic ones. ${ }^{28,30,31}$

Carboxylated cellulose nanofibers prepared by TEMPO (2,2,6,6-tetramethylpiperidine-1-oxyl)-mediated oxidation (TOCN) has carboxylate groups at C6 positions of the glucose unit of cellulose with sodium counterions. TOCN has been applied as binder and a material for composite separators for lithium ion batteries. ${ }^{8-10,16,32-35}$ A fabrication method of a separator using TEMPO-oxidized microbial cellulose was patented. ${ }^{33,34}$ Leijonmarck et al. $^{10}$ employed wood-based TOCN as binder and separator in integrated flexible trilayered lithium ion batteries. Fabrication of flexible lithium iron phosphate and graphite electrodes for lithium ion batteries using only 4 wt $\%$ of TOCN with good mechanical properties and cycling performance was reported by $\mathrm{Lu}$ et al. ${ }^{8,35} \mathrm{Liu}$ et $\mathrm{al}^{32}$ reported on a poly(vinyl alcohol) (PVA)/cellulose nanofiber $-\mathrm{Li}^{+}$composite separator, ${ }^{32}$ with $2 \%$ of TOCN. TOCN added enhanced mechanical strength of the PVA separator, but also slightly increased its porosity. Kim et al. ${ }^{16}$ used TOCN as the top layer of macroporous electrospun membranes. TOCN not only played the role of a pore sizecontrolling layer, but also as a functionalized surface conjugated with terpyridine (TPY), which chelates manganese ions $\left(\mathrm{Mn}^{2+}\right)$ from lithium manganese oxide positive electrodes, preventing $\mathrm{Mn}^{2+}$-induced adverse side effects.

In this study, TOCN based membranes with desired porosity as separators were successfully produced. Mesoporous membranes were fabricated by a conventional paper-making process, filtering an aqueous TOCN suspension, without addition of toxic dispersants or additional porogens. The rate capabilities and cyclability of TOCN separators with sodium carboxylated groups (TOCN-COO${ }^{-} \mathrm{Na}^{+}$) and carboxylic groups (TOCN-COOH) was studied. Our results demonstrate that TOCN-COOH battery separators made solely from wood fibers can give excellent electrochemical performance and stability.

\section{MATERIALS AND METHODS}

2.1. Materials. Never dried cellulose pulp was supplied by Domsjö Fabriker AB (Domsjö, Örnsköldsvik, Sweden). TEMPO radical (2,2,6,6-tetramethylpiperidine-1-oxyl, free radical, 98\%) was purchased from Alfa Aesar and sodium hypochlorite $(\mathrm{NaClO})$ and sodium bromide $(\mathrm{NaBr})$ from Sigma-Aldrich. All of the solvents used for the sequential solvent exchange, ethanol $96 \%$, acetone $\geq 99.8 \%, n$ Pentane $\geq 99 \%$, and hydrochloric acid ( $\mathrm{HCl}) 37 \%$ were purchased from VWR Chemicals and used as received. Durapore membrane filters (pore size $0.22 \mu \mathrm{m}$, Millipore) were used for filtration. Dialysis bags were purchased from Sigma-Aldrich (cutoff of $14 \mathrm{kDa}$ ). To build the battery cells, lithium nickel manganese cobalt oxide positive electrodes (NMC, $\mathrm{LiNi}_{1 / 3} \mathrm{Mn}_{1 / 3} \mathrm{Co}_{1 / 3} \mathrm{O}_{2}$ ) and graphite negative electrodes were purchased from ElectrodesAndMore (United States). Selectilyte LP 40 from BASF, composed of $1 \mathrm{M} \mathrm{LiPF}_{6}$ in ethylene carbonate (EC): diethyl carbonate (DEC) 1:1 by weight, was used as a liquid electrolyte. The current collectors, aluminum foil $(25 \mu \mathrm{m}$ thick) and copper foil $(20 \mu \mathrm{m})$, were purchased from Advent Research Materials and were used at the positive and negative electrodes, respectively.

2.2. Preparation of TOCN Membranes and Protonation. Never dried cellulose pulp was oxidized according to our previous study, ${ }^{8}$ following the earlier reported protocols by Saito et al. ${ }^{36}$ First, $40 \mathrm{~g}$ (dry content) of pulp were washed with a $\mathrm{HCl}$ solution at $\mathrm{pH} 2$ and suspended in deionized water followed by mixing with TEMPO (4 mmol) and $\mathrm{NaBr}(40 \mathrm{mmol}) . \mathrm{NaClO}(37.5 \mathrm{mmol})$ was slowly added to the suspension to achieve the desired amount of sodium carboxylated functional groups on the cellulose surface. The $\mathrm{pH}$ of the suspension was controlled and maintained to 10 during the reaction using a $0.5 \mathrm{M}$ sodium hydroxide solution. The charge density of the TEMPO-oxidized cellulose was determined to be $350 \mu \mathrm{mol} \mathrm{g}$ (carboxylate content per unit mass of fiber) by conductometric measurements. ${ }^{37}$ One weight percent TEMPO-mediated oxidized cellulose pulp suspended in water was disintegrated by a microfluidizer (M-110EH, Micro fluidics Corp, United States) and passed once through the 400 and $200 \mu \mathrm{m}$ chambers connected in series at 925 bar. The fibers obtained in this well-dispersed aqueous suspension containing $1 \mathrm{wt} \%$ of TEMPO-oxidized cellulose nanofibers are here named TOCN. The membrane was obtained by further diluting the TOCN suspension to $0.1 \mathrm{wt} \%$ and then vacuumfilteration through a Durapore membrane followed by sequential solvent exchange using $96 \%$ ethanol, acetone and pentane. A circular membrane of $3.5 \mathrm{~cm}$ diameter was dried overnight in a vacuum drier at $110{ }^{\circ} \mathrm{C}$. The (not protonated) fibers used to prepare such membranes are denoted as TOCN-COO${ }^{-} \mathrm{Na}^{+}$.

For protonation, the TOCN aqueous suspension was diluted to 0.1 wt $\%$ using a $10 \mathrm{mM} \mathrm{HCl}$ aqueous solution. The vacuum filtration was carried out in a similar fashion as before but a $1 \% \mathrm{v} / \mathrm{v}$ of a $1 \mathrm{M} \mathrm{HCl}$ solution was added to each solvent to maintain acidic condition. The filtered membranes were dried overnight in a vacuum drier at $110^{\circ} \mathrm{C}$. The protonated fibers used to prepare the membranes are denoted as TOCN-COOH.

Similar to an earlier reported procedure, ${ }^{8}$ individualized nanofibrils (denoted as TOCN-fibrils) were produced by mechanical disintegration of the pulp, passing $1 \%$ of the oxidized pulp aqueous suspension through the chambers in the microfluidizer. The suspension was passed 3 times through 400 and $200 \mu \mathrm{m}$ chambers connected in series at 925 bar and then additionally 6 times through two 200 and $100 \mu \mathrm{m}$ small chambers at 1600 bar. The membrane made of $0.1 \%$ TOCNfibril suspension was fabricated employing the same filtration and solvent exchange steps, as above.

2.3. Characterization of TOCN Membranes. Membrane thickness was measured using a Mitutoyo Digimatic 293-521-30 digital micrometer. Three different methods were employed to measure the porosities of different separators. First, bulk porosities of the separators were measured using a butanol uptake method $\left(p^{\mathrm{BuOH}}\right),{ }^{38}$ see eq 1 . The separator mass was measured before and after immersion in butanol for $2 \mathrm{~h}$

$$
\text { porosity, } p^{\mathrm{BuOH}}(\%)=\frac{\frac{m_{\mathrm{a}}}{\rho_{\mathrm{a}}}}{\left(\frac{m_{\mathrm{a}}}{\rho_{\mathrm{a}}}+\frac{m_{\mathrm{b}}}{\rho_{\mathrm{b}}}\right)}
$$

with the variables $m_{\mathrm{a}}$ (mass of butanol, $\mathrm{g}$ ), $\rho_{\mathrm{a}}$ (density of butanol, 0.81 $\mathrm{g} / \mathrm{cm}^{3}$ ), $m_{\mathrm{b}}$ (mass of separator, $\mathrm{g}$ ), and $\rho_{\mathrm{b}}$ (density of separator material, cellulose, $1.5 \mathrm{~g} / \mathrm{cm}^{3}$ ).

Second, nitrogen adsorption analysis was performed to measure the pore size distribution and the porosity of TOCN-COOH membrane. Prior to the nitrogen adsorption analysis, $100 \mathrm{mg}$ of dried TOCN$\mathrm{COOH}$ membranes (mass, $\mathrm{g}$ ) were degassed overnight using dry $\mathrm{N}_{2}$ at $80{ }^{\circ} \mathrm{C}$. The surface area and the average pore size distribution were determined by nitrogen sorption analysis using a Micromeritics Gemini VII at $-194{ }^{\circ} \mathrm{C}$. Pore volume and pore size distributions of mesopores were calculated using the Barrett-Joyner-Halenda (BJH) model. ${ }^{39}$ Total pore volume (TOPV, $\mathrm{cm}^{3} / \mathrm{g}$ ) obtained enables to evaluate porosity of the TOCN-COOH $\left(p^{\text {ads }}\right)$ using eq 2 . 


$$
\text { porosity, } p^{\text {ads }}(\%)=\frac{\mathrm{TOPV} \cdot m_{\mathrm{b}}}{\frac{m_{\mathrm{b}}}{\rho_{\mathrm{b}}}+\mathrm{TOPV} \cdot m_{\mathrm{b}}}=\frac{\mathrm{TOPV}}{\frac{1}{\rho_{\mathrm{b}}}+\mathrm{TOPV}}
$$

Lastly, morphological features of TOCN and TOCN-fibril membranes were observed by a Hitachi S-4800 field emission scanning electron microscopy (FE-SEM) operated at $1 \mathrm{kV}$. The specimens were mounted on aluminum stubs and sputtered with a thin layer of $\mathrm{Pt} / \mathrm{Pd}$.

The apparent surface porosities and pore width distribution on each side of the membranes were obtained from image analysis of micrographs acquired at 60000 magnification using the ImageJ software v1.51j8. ${ }^{40}$ To do this, the gray scale of the SEM images was adjusted to remove empty levels followed by binarization and thresholding above the noise level. The pore size distribution was obtained using the particle analysis routine in Image J assuming elliptical pores. The determined area values were then converted into equivalent diameters. The lowest and highest pore width cutoffs were set at 3 and $90 \mathrm{~nm}$, respectively.

Single nanofibers dispersed of microfibrillated cellulose were observed by a scanning electron microscope (JEOL JSM-7401F, 20 $\mathrm{kV}$ ) in transmission mode (STEM). A suspension with a CNF concentration of $0.001 \mathrm{wt} \%$ was prepared and deposited on a grid suitable for electron microscopy (ultrathin carbon on holey carbon, 400 mesh copper). A drop was deposit on the grid and excess water was wiped away with filter paper. After water was evaporated, the sample was ready to image. The size distribution of CNF with widths of less than $1 \mu \mathrm{m}$ were also analyzed using the same software ImageJ.

A PerkinElmer Spectrum 100 Fourier transform infrared (FTIR) spectrometer was used to estimate the protonation of sodium carboxylate to carboxylic acid in TOCN-COOH and TOCN$\mathrm{COO}^{-} \mathrm{Na}^{+}$membranes. The membranes were analyzed under transmission mode from 600 to $4000 \mathrm{~cm}^{-1}$ with a $4 \mathrm{~cm}^{-1}$ resolution.

The thermal stability of TOCN was investigated at elevated temperature. $3.5 \mathrm{~cm}$-diameter circular specimens of TOCN and Celgard 2325, a commercial, reference polyolefin separator, were placed in an oven at $150{ }^{\circ} \mathrm{C}$ up to $15 \mathrm{~min}$ and their dimensional changes were observed. Thermogravimetric analysis was performed with a Mettler Toledo TGA/DSC 1 to analyze the decomposition behavior of TOCN materials at high temperature. Samples were mounted in $70 \mu \mathrm{L}$ alumina crucibles and heated from room temperature to $110{ }^{\circ} \mathrm{C}$ at the rate of $10{ }^{\circ} \mathrm{C} / \mathrm{min}$ with a holding step of $30 \mathrm{~min}$ at $110^{\circ} \mathrm{C}$. Afterward, the temperature was increased to $500{ }^{\circ} \mathrm{C}$ at the rate of $10 \mathrm{~K} / \mathrm{min}$ and maintained at $500{ }^{\circ} \mathrm{C}$ for $30 \mathrm{~min}$, prior to cooling.

2.4. Electrochemical Measurements. The resistivity of the electrolyte in the TOCN membranes was measured in a pouch cell using two symmetric copper electrodes. A membrane soaked in electrolyte was sandwiched between the electrodes and sealed in an argon-filled glovebox. The resistivity was determined by AC impedance measurements in the frequency range between $10^{2}$ and $3 \times 10^{5} \mathrm{~Hz}$ with an amplitude of $10 \mathrm{mV}$, using a Gamry PCI4 G750 potentiostat. The measured bulk resistance, $R_{\mathrm{b}}$, was converted to ionic conductivity, $\sigma$, using eq 3 , where $L$ is the thickness of the membrane (in $\mathrm{cm}$ ) and $A$ the area $\left(\right.$ in $\mathrm{cm}^{2}$ ).

$$
\sigma(\mathrm{mS} / \mathrm{cm})=\frac{L}{\left(R_{\mathrm{b}} \times A\right)}
$$

The electrochemical stability of the separators was measured by linear sweep voltammetry (LSV) with a scan rate of $1 \mathrm{mV} / \mathrm{s}$ at a potential range from 2.6 to $6 \mathrm{~V}$ versus $\mathrm{Li}^{+} / \mathrm{Li}$. A $1.5 \mathrm{~cm}$-diameter circular lithium plate was used as a counter and reference electrode with a nickel current collector, whereas a stainless steel plate was used as a working electrode with an aluminum current collector.

For cycling performance tests, pouch cells consisting of $\mathrm{LiNi}_{1 / 3} \mathrm{Mn}_{1 / 3} \mathrm{Co}_{1 / 3} \mathrm{O}_{2}$ (NMC) as positive electrode, graphite as negative electrode, and the cellulose-based membranes previously described as separators soaked in electrolyte were assembled in an argon-filled glovebox $\left(<1 \mathrm{ppm}\right.$ of $\mathrm{O}_{2}$ and $\left.\mathrm{H}_{2} \mathrm{O}\right)$. Celgard 2325 was used as a reference separator and its electrochemical performance was compared with that of the TOCN separators. Galvanostatic cyclic performance tests were carried out using a BioLogicVMP-300 multipotentiostat. The cells were cycled at $0.1 \mathrm{C}$ for 4 cycles and subsequently at $1 \mathrm{C}$ charging rate in the potential range between 2.6 to $4.1 \mathrm{~V}$ versus $\mathrm{Li}^{+} / \mathrm{Li}$ for 100 cycles. The discharging rate capabilities were examined using a Solartron 1286 Electrochemical Interface potentiostat controlled with the CorrWare software. The cells were charged at $0.2 \mathrm{C}$ rate using a constant current-constant voltage $(\mathrm{CCCV})$ protocol with a limiting current of $0.04 \mathrm{C}$ and discharged at 0.1 to $5.0 \mathrm{C}$ using a constant current (CC), all in the potential window between 2.6 and $4.1 \mathrm{~V}$ versus $\mathrm{Li}^{+} / \mathrm{Li}$. After the discharging rate capability test, the cell containing the TOCN-COO ${ }^{-} \mathrm{Na}^{+}$ separator was opened in an argon-filled glovebox. A used electrode, a Celgard 2325 separator and a lithium metal counter electrode were assembled and the half-cells tested at $0.04 \mathrm{C}$ rate. The remaining capacity of each electrode was measured to compare with that of fresh NMC and graphite electrodes.

\section{RESULTS AND DISCUSSION}

3.1. Physical Properties and Morphology of TOCN Membranes. Morphologies of TOCN separators are displayed in Figure 1. No significant difference was observed in the morphology of the membranes before (TOCN$\mathrm{COO}^{-} \mathrm{Na}^{+}$, Figure $1 \mathrm{a}$ and c) and after protonation (TOCN$\mathrm{COOH}$, Figure $1 \mathrm{~b}$ and $\mathrm{d}$ ).

Membranes fabricated by the filtration process have an asymmetric structure as a consequence of the filtration process. Herein, the side of the TOCN membranes in contact with the Durapore filter is denoted as the bottom side, and the side exposed to air is the top side. The top side has a rougher surface and larger pores of micrometer size (Figure 1a and b),
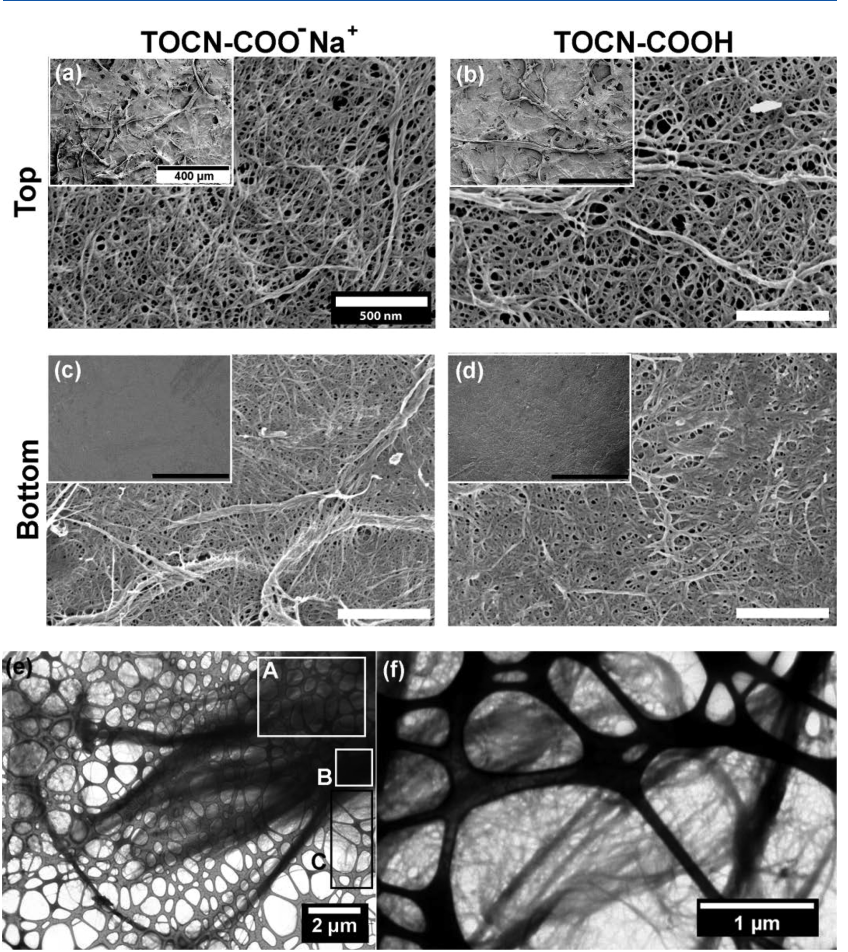

Figure 1. SEM images of TOCN membranes before (TOCN$\mathrm{COO}^{-} \mathrm{Na}^{+}$, a and c) and after protonation ( $\mathrm{TOCN}-\mathrm{COOH}, \mathrm{b}$ and $\mathrm{d}$ ), and STEM images of a TOCN single microfiber in transmission mode at low (e) and high magnification (f). Among SEM images a-d, first and second rows correspond to the top and bottom sides of the membrane, respectively. The black scale bars in the bottom right-hand corners correspond to $400 \mu \mathrm{m}$, whereas white ones to $500 \mathrm{~nm}$. 
whereas the bottom side has a flatter and more compact surface, particularly seen in Figure $1 \mathrm{c}$ and $\mathrm{d}$.

The TOCN used is composed of micro- and nanofibrils with various dimensions, as shown in Figure 1, and the membranes have multiscale porous structures. Macropores observed at the low magnification (Figure $1 \mathrm{a}$ and $\mathrm{b}$ ) can facilitate liquid electrolyte uptake. At the high magnification, it is observed that the membranes have mesoporous structures, desirable for lithium ion battery separators. ${ }^{41}$ Micrometer-sized fibers mainly observed at the low magnification (Figure 1a and b) may play a role to prevent significant dimensional shrinkage of the TOCN membrane after the fast drying. Nanofibrils interconnect the microfibers, forming a densely packed surface.

The morphology of a single microfiber was investigated by using STEM in transmission mode (Figure le and $\mathrm{f}$ ). As shown in $A$ and $B$ of Figure 1e, the TOCN microfiber is partially disintegrated. Compared to the dark part B in Figure 1e, a partially transparent part shown at A in Figure le is likely less dense and more loosened, seemingly a porous structure. It implies that the micro sized fibers are not a physical barrier but rather ions can possibly pass through the micro sized fibers when it is applied as a membrane material. Numerous nanofibrils exfoliated from the main body of the microfiber were also observed in Figure 1e $\mathrm{C}$ and $\mathrm{f}$. Ultimately, the presence of both of micro- and nanofibers enables to fabricate a CNF separator with desired physical properties as a lithium ion battery separator. The average width of nanofibers was 130 $\mathrm{nm}$, but also the widths of more than $50 \%$ of nanofibers were less than $66 \mathrm{~nm}$ (Figure S1). The histogram was fitted by a lognormal distribution as the function of fiber widths. The mean value was $122 \mathrm{~nm}$, which was the very similar value with the average fiber width calculated by multinomial distribution. Therefore, the carboxylated surface charge introduced by TEMPO mediated oxidation ensures the electrostatic repulsion between cellulose fibers and efficient defibrillation by mechanical treatment with the homogenizer.

Moreover, it implies that the mesopores in the TOCN membrane originate from the porous fiber structure, showing a similar morphological feature to that of the dried membranes observed by SEM (Figure 1a-d). Furthermore, the intra- and interpores in fibers were well maintained without significant pore closure during protonation, filtration, and drying, which is attributed to the dimensional stability of the microfibers and the solvent exchange process. Fast protonation during filtration is advantageous compared to dialysis, as explained in the SI (Figure S2).

Regarding the mechanical and chemical energy input and the desirable nanostructure, the process in this study required much less energy, compared to the typical CNF producing process. For example, kraft pulp fibers were treated more than 120 times using an ultrafine grinder to obtain CNF. ${ }^{42}$ Chun et al. produced CNF passing cellulose fibers 12 times through a microfluidizer. ${ }^{12}$ Previous studies which pursued full dispersion of cellulose fibers to nanofibrils ${ }^{8,43,44}$ required high degrees of charge density, $600-1500 \mu \mathrm{mol} / \mathrm{g}$, whereas for $350 \mu \mathrm{mol} / \mathrm{g}$, the extent of chemical modification enabled to produce CNF by passing the fibers through a microfluidizer just once.

The physical properties of TOCN membranes before and after protonation as well as that of a Celgard 2325 separator are listed in Table 1.

We measured the porosities of TOCN membranes by three different methods-butanol immersion, nitrogen adsorption and SEM image analysis. First of all, overall porosities of the
Table 1. Comparison of Physical Properties of Celgard 2325 and TOCN Separators

\begin{tabular}{|c|c|c|c|c|}
\hline & $\begin{array}{c}\text { porosity } \\
(\%)\end{array}$ & $\begin{array}{l}\text { thickness } \\
\qquad(\mu \mathrm{m})\end{array}$ & $\begin{array}{c}\text { ionic } \\
\text { conductivity } \\
(\mathrm{mS} / \mathrm{cm})\end{array}$ & $\begin{array}{l}\text { electrolyte } \\
\text { uptake (\%) }\end{array}$ \\
\hline Celgard 2325 & $46 \pm 2$ & $23 \pm 2$ & $0.81 \pm 0.02$ & $85 \pm 4$ \\
\hline TOCN-COO ${ }^{-} \mathrm{Na}^{+}$ & $59 \pm 2$ & $29 \pm 4$ & $0.85 \pm 0.03$ & $\geq 200$ \\
\hline TOCN-COOH & $62 \pm 3$ & $34 \pm 4$ & $1.06 \pm 0.07$ & $\geq 200$ \\
\hline
\end{tabular}

membranes, including micro-, meso-, and macropores, were measured by immersing the membranes in butanol, see results in Table 1. A slightly higher thickness of the TOCN-COOH membrane is attributed to aggregation due to loss of surface charge at acidic conditions. ${ }^{43}$ The porosity of Celgard 2325 measured by butanol immersion was $46 \pm 2 \%$, whereas $39 \%$ porosity is the specification from the supplier.

Nitrogen adsorption was used to measure the total pore volume and the pore size distribution of mesopores in the TOCN-COOH separator. The nitrogen adsorption isotherm and BET surface area curves for TOCN-COOH membrane are displayed in Figure S3. The average pore width is determined to $13.3 \mathrm{~nm}$ (Figure 2) and the BET surface area is $38.3 \mathrm{~m}^{2} / \mathrm{g}$.

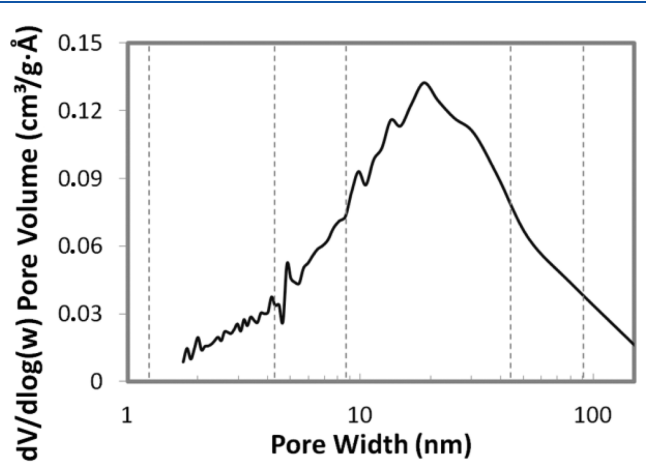

Figure 2. Pore size distribution of a TOCN-COOH separator.

Total volume of mesopores is $0.141 \mathrm{~cm}^{3} / \mathrm{g}$, which corresponds to $17 \%$ of the porosity, according to eq 2 . Compared to the overall porosity measured by a butanol immersion, shown in Table 1 , the value is much lower, which indicates that macro pores take a much higher proportion than that of mesopores.

The porosities of the top and bottom sides of the TOCN membranes were separately investigated using SEM images in Figure 1 and binary images in Figure S4.

Figure 3 illustrates the pore size distribution of each side of the TOCN membranes. Average pore widths of the top and bottom sides of TOCN membranes are almost similar, as well as the value measured by nitrogen adsorption. The porosities of the top side of TOCN-COOH and of TOCN-COO- $\mathrm{Na}^{+}$ are similar and it is approximately twice those of the bottom sides. Seeing Figure 1,a and b, a high proportion of macropores are on the top side, whereas the flat bottom side barely has any macropores (Figure 1c and d). Considering the distribution of macropores, the porosities of the top sides of the separators can be significantly higher than that of bottom sides. This can explain the different discharging rate capabilities during battery cycling shown in section 3.4.

The porosity of Celgard 2325 separator measured by the same image analysis was $22.2 \pm 3.4 \%$ and the average pore radius was $34.2 \mathrm{~nm}$. The porosities were much lower than the values suggested by the supplier or measured by different 

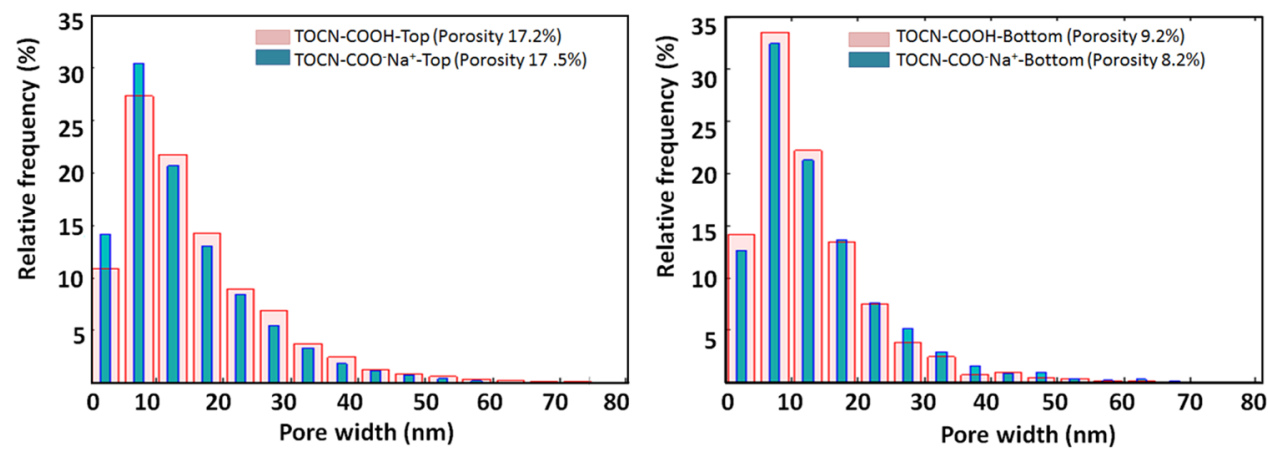

\begin{tabular}{ccccc}
\hline & \multicolumn{2}{c}{ TOCN-COOH } & \multicolumn{2}{c}{ TOCN-COO-Na ${ }^{+}$} \\
\hline & Top & Bottom & Top & Bottom \\
\hline Porosity (\%) & $17.5 \pm 1.6$ & $9.2 \pm 1.6$ & $17.2 \pm 2.2$ & $8.2 \pm 2.2$ \\
Average pore width $(\mathrm{nm})$ & $19.7 \pm 11.8$ & $16.5 \pm 9.2$ & $17.7 \pm 10.5$ & $16.0 \pm 10.1$ \\
\hline
\end{tabular}

Figure 3. Histograms of pore size distributions of top and bottom sides of $\mathrm{TOCN}-\mathrm{COOH}$ and $\mathrm{TOCN}-\mathrm{COO}^{-} \mathrm{Na}^{+}$membranes.

analytical techniques; X-ray microscope ${ }^{46}$ and butanol immersion above. It is because Celgard 2325 has a difference in porosity with depth whereas FE-SEM has limitation to analyzing depth-specific porosities. Nevertheless, the surface porosity measurements by image analysis gave better understanding about the pore structure of these membranes.

TOCN fibril membranes were fabricated using the same filtration and solvent exchange method as above. The membranes demonstrated a slight dimensional shrinkage with a reduced diameter from 3.5 to $3.3 \mathrm{~cm}$ (Figure S5b) and, consequently, a denser morphology (Figure S5c), compared to that of TOCN membrane (Figures 1 and S5a). This implies that a delicate drying process, such as freeze-drying or supercritical drying, is required when using finely dispersed cellulose nanofibrils, in order to prevent dimensional shrinkage and pore collapse. ${ }^{47}$

Thermal stability of the TOCN-COOH membranes and Celgard 2325 is reported in the Supporting Information (Figure S6). It demonstrated that the thermal stability of TOCN-COOH has slightly improved by protonation, compared to that of TOCN-COO ${ }^{-} \mathrm{Na}^{+}$.

3.2. Protonation of Carboxylate Groups. To confirm the complete protonation via the filtration process, functional groups in the surface of TOCN-COO${ }^{-} \mathrm{Na}^{+}$and TOCN$\mathrm{COOH}$ were analyzed by FT-IR spectra, as shown in Figure 4. The peak at $1610 \mathrm{~cm}^{-1}$ indicates carbonyl absorption in sodium carboxylate groups in the TOCN-COO ${ }^{-} \mathrm{Na}^{+}$membrane. After protonation, the peak is shifted to $1724 \mathrm{~cm}^{-1}$,

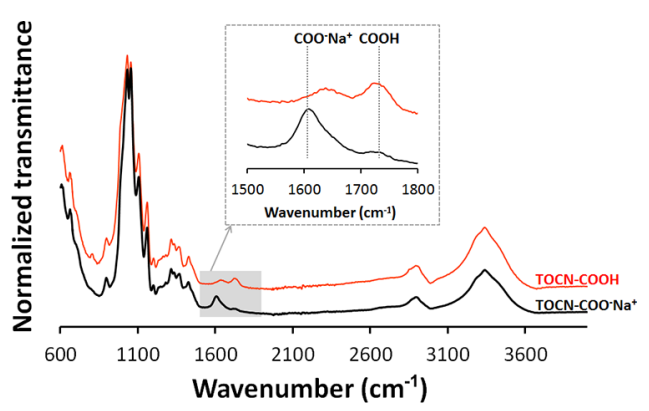

Figure 4. FT-IR spectra of TOCN membranes before and after protonation. which corresponds to stretching of carbonyl groups of the protonated carboxylate groups $(\mathrm{COOH})$. The broad peak at $1632 \mathrm{~cm}^{-1}$ is associated with the $\mathrm{O}-\mathrm{H}$ bending vibration of absorbed water, which partially overlaps with carbonyl absorption in sodium carboxylate groups in $\mathrm{TOCN}-\mathrm{COO}^{-} \mathrm{Na}^{+}$ $\left(1610 \mathrm{~cm}^{-1}\right)$, whereas more noticeable in TOCN-COOH, as the peak at 1610 shifts to 1724 . Because of its hygroscopic characteristics, a time-dependent increase in intensity of adsorbed water peaks at 3300 and $1632 \mathrm{~cm}^{-1}$ hinders quantification of the precise amount of adsorbed water associated with the sodium counterions.

3.3. Electrochemical Performances of TOCN Separators in Lithium Ion Batteries. The electrochemical stability of TOCN separators and their performance in lithium ion batteries were investigated by galvanostatic charging/discharging cycling tests (Figure 5) and linear sweep voltammetry (Figure S7). Figure 5 presents electrochemical performances of the cells with different separators at $0.1 \mathrm{C}$ of charging and discharging $\left(0.15 \mathrm{~mA} / \mathrm{cm}^{2}\right)$ for 4 cycles. The cell with TOCN$\mathrm{COO}^{-} \mathrm{Na}^{+}$showed a significant decrease in specific capacity after two cycles in spite of its promising morphology (Figure $1 \mathrm{a}-\mathrm{c}$ ), whereas the cells containing Celgard 2325 and TOCN$\mathrm{COOH}$ separators demonstrated excellent cyclic stability for 4 cycles.

After the cycling test of the cell containing TOCN$\mathrm{COO}^{-} \mathrm{Na}^{+}$(Figure 5a), the pouch cell was slightly swollen, indicating gas evolution accompanied by degradation of the battery components. To investigate if the TOCN-COO${ }^{-} \mathrm{Na}^{+}$ separator resulted in damage of the electrodes, the used electrodes were taken from the full cell and reassembled in half-cells with lithium metal counter electrodes and Celgard 2325 separators. Those cells were tested at $0.04 \mathrm{C}$ of charging rate and the remaining capacities were measured. Unlike the significantly decreased specific capacity of the full cell containing the TOCN-COO${ }^{-} \mathrm{Na}^{+}$separator, the specific capacities of the used NMC and graphite were 121 and 344 $\mathrm{mAh} / \mathrm{g}$, respectively. Considering the specific capacities of a fresh NMC electrode $(147 \mathrm{mAh} / \mathrm{g})$ and a fresh graphite electrode $(370 \mathrm{mAh} / \mathrm{g})$, the electrodes lost approximately $10 \%$ of their specific capacities, which means the electrodes had not been much affected by the TOCN-COO${ }^{-} \mathrm{Na}^{+}$separator. 


\section{(a) TOCN-COO- $\mathrm{Na}^{+}$}

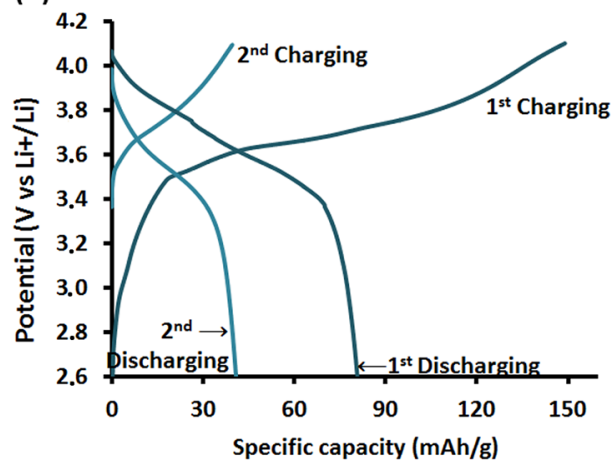

(b) $\mathrm{TOCN}-\mathrm{COOH}$

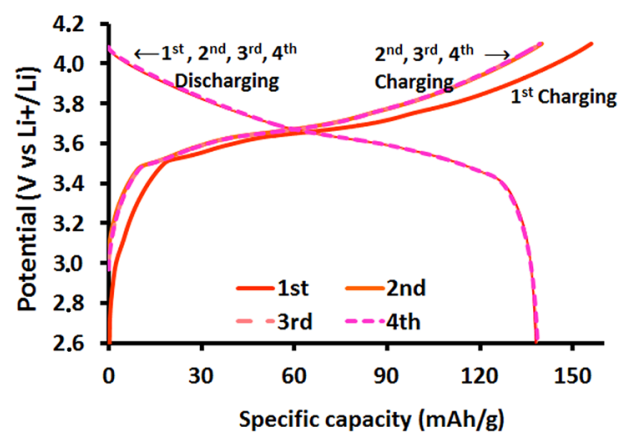

(c) Celgard2325

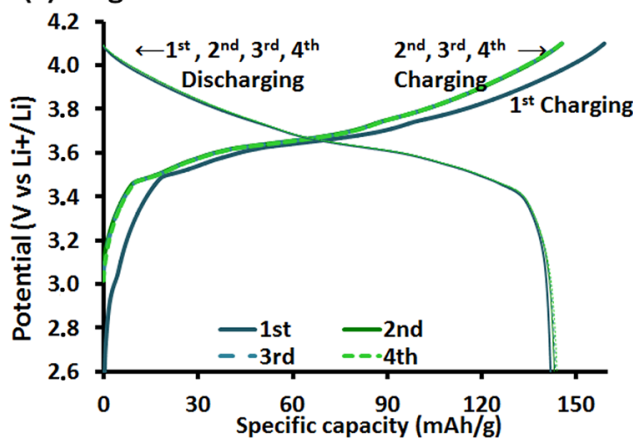

Figure 5. Electrochemical performances of the LiNMC/Graphite cells with different separators at $0.1 \mathrm{C}$ charging/discharging rate: (a) TOCN-COO ${ }^{-} \mathrm{Na}^{+}$, (b) TOCN-COOH, and (c) Celgard 2325.

Another possible reason resulting in the significant capacity decrease is attributed to degradation of electrolyte due to the presence of water. It is well-known that water leads to adverse side effects in lithium ion batteries. ${ }^{48-50}$ Pentafluorophosphate $\left(\mathrm{PF}_{5}\right)$ formed because of decomposition of hexafluorophosphate $\left(\mathrm{PF}_{6}\right)$, additive salt in electrolyte, is a strong Lewis acid, which can react with water and decompose electrolyte. Thus, trace amounts of water in a material should be carefully considered, especially when using hygroscopic materials such as cellulose. There are three different types of adsorbed water on the surface of cellulose: ${ }^{51,52}$ free water, freezable bound water, and nonfreezable water. Free water can be easily removed during a normal drying process at high temperature. On the contrary, as bound water forms strong bonds with surface functional groups, it requires a much higher amount of energy to get rid of water. Especially, nonfreezable bound water is closely associated with a polymer matrix without phase transition in calorimetric analysis. Depending on the source and chemical/mechanical treatment, cellulose materials can vary in degree of crystallinity, surface chemistry and water sorption behavior. ${ }^{52-55}$ Wood-based cellulose has lower crystallinity compared to non-wood-based cellulose, such as microbial- or algae cellulose. Chemically modified wood-based cellulose with low crystallinity can contain a high amount of bound water. ${ }^{5,56}$ Such properties of wood-based cellulose nanofibers make its application to lithium ion batteries demanding.

In this work, we got inspiration from the literature showing that the amount of bound water on the cellulose depends on the type of counter cations of the surface groups. Berthold et al., ${ }^{52,57}$ reported that the amount of bound water of CMC with sodium carboxylate groups becomes 2-4 times higher than that of the protonated counterpart. Leijonmarck et al. ${ }^{9,10}$ reported that electrochemical performances of flexible lithium ion batteries containing TOCN binders or separator varied depending on drying conditions. Accordingly, the protonation of TOCN dramatically improved the performance of the TOCN separators. Therefore, removal of water substituting sodium ions to protons is likely a key factor for applying wood based TOCN for lithium ion batteries.

It is also important to investigate the electrochemical stability of a separator material, especially in the operating potential range of the batteries. Figure S7 presents LSV results of TOCN separators and Celgard 2325, and they behave very similar. The rapid increase in current over $5 \mathrm{~V}$ is attributed to the decomposition of the carbonate electrolyte at high potentials. This result indicates that TOCN-COOH separators have good compatibility with the liquid carbonate electrolyte and can be considered as stable as a polyolefin.

Cycling curves in Figure 6 show that the discharging specific capacity of the cell with a TOCN-COOH separator at the first cycle was $109.5 \mathrm{mAh} / \mathrm{g}$ and after 100 cycles $103.5 \mathrm{mAh} / \mathrm{g}$, thus
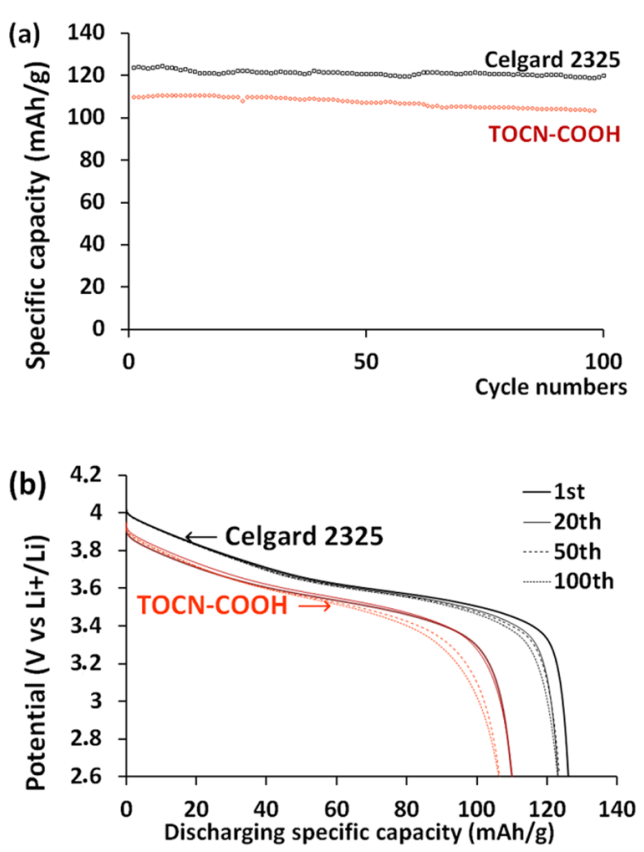

Figure 6. Electrochemical performances of TOCN-COOH and Celgard 2325 separators tested in LiNMC/Graphite cell. (a) Galvanostatic fast charging and discharging cyclic stability test at 1 $\mathrm{C}$ and (b) discharging polarization curves of the cells at 1st, 20th, 50th, and 100th cycles. 
(a)

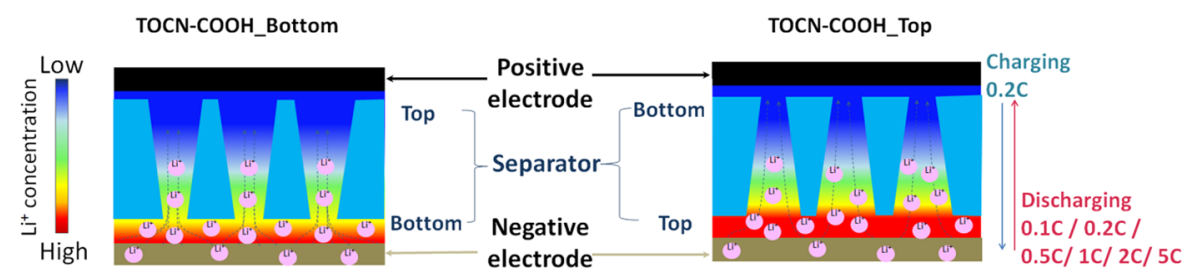

(b)
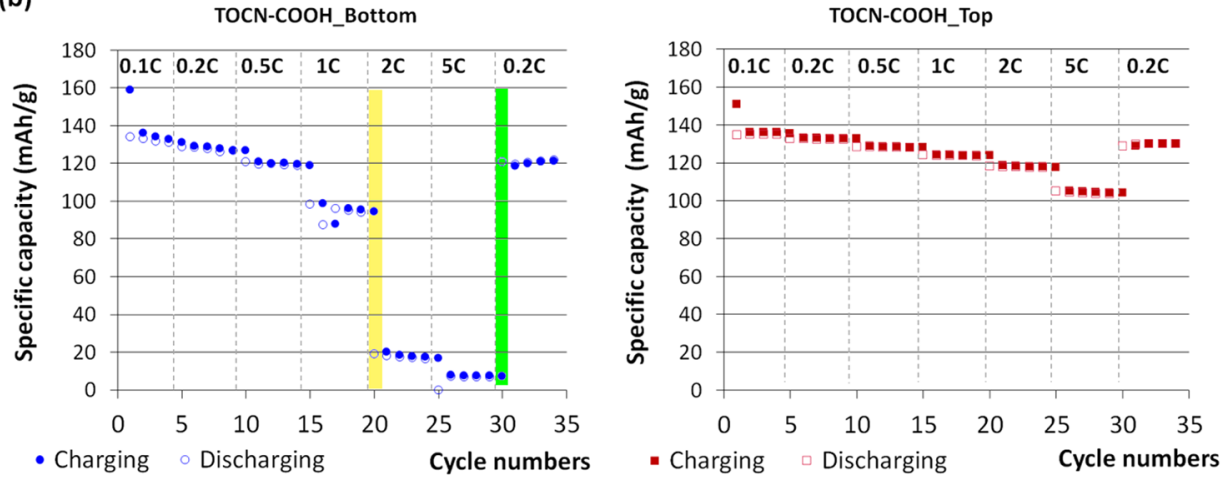

Figure 7. Schemes of the cell configurations varying the orientation of asymmetric TOCN-COOH membranes and illustration of lithium ion flux through the surface of separators (a). The discharging rate capabilities of the cells above, charged at $0.2 \mathrm{C}$ and discharged at different rates (b).

94.5\% of the discharging capacity remained. The battery cell containing the Celgard 2325 separator had $123.5 \mathrm{mAh} / \mathrm{g}$ of the initial discharging specific capacity and $119.7 \mathrm{mAh} / \mathrm{g}$ after 100 cycles, corresponding to $96.9 \%$ of initial discharging capacity. Higher ohmic loss and relatively lower specific capacity (Figure $6 \mathrm{~b})$ of the $\mathrm{TOCN}-\mathrm{COOH}$ cell were attributed to its higher thickness, and possibly a different pore structure, compared to that of Celgard 2325 (Figure S8a). Another reason for the lower capacity is possibly interaction between the liquid electrolyte and cellulose based materials. ${ }^{58}$ Xiao et al. also reported that possible reactions between hydroxyl groups in cellulose and lithium can result in increased interfacial resistance during the charging and discharging process, compared to that of an inert polyolefin based separator. ${ }^{25}$ Pan et al. suggested that it is possible that hydroxyl groups in the surface of cellulose can retard the transport of liquid electrolyte. ${ }^{14}$ However, taking into account the Coulombic efficiency of the TOCN-COOH separator cell, comparable to that of the Celgard 2325 cell, this material can be considered as stable as polyolefin materials (Figure S9). Even though Zhu et al. $^{27}$ mentioned that carboxylic acid groups can facilitate the transport of ions in the liquid electrolyte, it is possible that extra hydroxyl groups can negatively influence on the battery performances. Therefore, additional research is required to investigate interactions of functional groups on the surface of cellulose materials and the liquid electrolyte.

3.4. Influence of Asymmetric Porous Structure of TOCN Separator on Rate Capabilities. In section 3.1, an asymmetric structure of TOCN separators produced by filtration and its different surface porosities were investigated. Taking into account its multiscale porous structure, the porosities of the top side are considerably larger than of that of the bottom side.

The full cell with an NMC positive electrode in contact with the porous top surface and graphite negative electrode contacting the denser and less porous bottom side of the separator is denoted as TOCN-COOH_Bottom. On the other hand, the cell with graphite in contact with the top side of the separator is denoted as TOCN-COOH_Top. Schematic descriptions of the cell configurations and lithium ion flux of each cell are illustrated in Figure $7 \mathrm{a}$. The performances of the cells were compared at different discharging rate $(0.1,0.2,0.5$, 1,2 , and $5 \mathrm{C}$ ), as shown in Figure $7 \mathrm{~b}$.

It can be seen that the lithium ion transport is highly dependent on the surface porosity, especially at high $\mathrm{C}$ rate. There was no significant difference in specific capacity of the cells at slow discharging rates $(0.1,0.2$, and $0.5 \mathrm{C})$. However, the specific capacity of the cell named TOCN-COOH_Bottom significantly decreased as the discharging rate increase $\bar{d}$ to over 1 C. Previous studies ${ }^{11,12,14}$ of the cellulose based separators with $<20 \mathrm{~nm}$ of the average pore size also reported a similar trend of rate capability results at fast charging/discharging. Even though the TOCN-COOH_Bottom cell was fully charged before first discharging at $\overline{2} \mathrm{C}$ (Figure $7 \mathrm{~b}$, yellow bar), it is barely discharged. This obviously shows that the capacity drop is not due to side reactions involving electrolyte and separator, since the specific capacity was recovered in the last 5 cycles of discharging tests at $0.2 \mathrm{C}$. Rather it is likely associated with low porosity of the bottom side as the bottleneck of migration of ions. On the contrary, the other cell, TOCN-COOH_Top, had higher discharging specific capacity, even at high $\bar{C}$-rate, comparable to that of Celgard 2325 (Figure S8b). This is probably because of improved mass transport at the top side of the membrane with higher overall porosity. Even though the asymmetric structure of the TOCN$\mathrm{COOH}$ seemed disadvantageous, under stable charging conditions and locating the separator in the specific orientation considering its structure, this separator can show excellent discharging rate capability, comparable to that of Celgard 2325 .

\section{CONCLUSION}

In the present work, we demonstrated that wood based TOCN can be used as a lithium ion battery separator with excellent 
electrochemical performance. Asymmetric TOCN-based membranes were fabricated as mesoporous membranes via a conventional paper-making technique and examined as lithium ion battery separators. The separator made of TOCN with sodium carboxylated surface groups (TOCN-COO${ }^{-} \mathrm{Na}^{+}$) showed a significant capacity fade in a few cycles of charging and discharging. On the other hand, protonated TOCN$\mathrm{COOH}$ membranes showed highly improved electrochemical performance, displaying $94.5 \%$ of discharge capacity maintained after 100 cycles at $1 \mathrm{C}$ rate of charging and discharging. The asymmetric porous structure of the membrane made by filtration requires attention when assembling a battery cell to reach excellent rate capabilities.

These results highlight the importance of taking account of chemical compositions of cellulose-based materials and chemically bound trace water in the dried states of cellulose. It is expected that such understanding will expand the applicability of cellulose nanofibers for nonaqueous solutionbased electronics. Further studies are required to investigate quantification of trace water in cellulose nanofibers and improvement of its feasibility for lithium ion batteries.

\section{ASSOCIATED CONTENT}

\section{S Supporting Information}

The Supporting Information is available free of charge on the ACS Publications website at DOI: 10.1021/acsaem.8b01797.

Size distribution of cellulose nanofibers, SEM images of morphology of dialyzed TOCN membrane, nitrogen adsorption isotherm and BET specific surface area for TOCN-COOH membrane, binary images of morphological features of TOCN membranes, circular membrane made of TOCN, dimensional shrinkage of TOCN-fibrils, SEM image of the TOCN-fibril membrane, thermal stability test of Celgard 2325 and of TOCN-COOH, thermogravimetric analysis of TOCN membranes before and after protonation, linear sweep voltammograms of TOCN and Celgard 2325, surface of a Celgard 2325 separator, rate capability performances of NMC/Graphite cell with Celgard 2325 separator, and coulombic efficiency of Celgard 2325 and TOCN$\mathrm{COOH}$ separators (PDF)

\section{AUTHOR INFORMATION}

\section{Corresponding Author}

*E-mail: hyeyun@kth.se.

\section{ORCID}

Hyeyun Kim: 0000-0001-9404-4087

Ann Cornell: 0000-0001-5816-2924

\section{Present Address}

${ }^{\mathbb{I}}$ H.L.: Northvolt AB, Gamla Brogatan 26, SE111 20, Sweden.

\section{Notes}

The authors declare no competing financial interest.

\section{ACKNOWLEDGMENTS}

This work was supported by the Knut and Alice Wallenberg Foundation and the authors also thank to the Wallenberg Wood Science Center for all the financial and technical supports.

\section{REFERENCES}

(1) Larcher, D.; Tarascon, J. M. Towards Greener and More Sustainable Batteries for Electrical Energy Storage. Nat. Chem. 2015, $7,19-29$.

(2) Grey, C. P.; Tarascon, J. M. Sustainability and in Situ Monitoring in Battery Development. Nat. Mater. 2017, 16, 45-56.

(3) Liu, J.; Zhang, Q.; Zhang, T.; Li, J.-T.; Huang, L.; Sun, S.-G. A Robust Ion-Conductive Biopolymer as a Binder for Si Anodes of Lithium-Ion Batteries. Adv. Funct. Mater. 2015, 25, 3599-3605.

(4) Prasanna, K.; Subburaj, T.; Jo, Y. N.; Lee, W. J.; Lee, C. W. Environment-Friendly Cathodes Using Biopolymer Chitosan with Enhanced Electrochemical Behavior for Use in Lithium Ion Batteries. ACS Appl. Mater. Interfaces 2015, 7, 7884-7890.

(5) Moon, R. J.; Martini, A.; Nairn, J.; Simonsen, J.; Youngblood, J. Cellulose Nanomaterials Review: Structure, Properties and Nanocomposites. Chem. Soc. Rev. 2011, 40, 3941-3994.

(6) ISO. Nanotechnologies-Standard Terms and Their Definition for Cellulose Nanomaterial, ISO/TS 20477:2017; International Organization for Standardization, 2017.

(7) TAPPI. Proposed New TAPPI Standard: Standard Terms and Their Definition for Cellulose Nanomaterial; Technical Association of Pulp and Paper Industry, 2011.

(8) Lu, H.; Guccini, V.; Kim, H.; Salazar-Alvarez, G.; Lindbergh, G.; Cornell, A. Effects of Different Manufacturing Processes on TEMPOOxidized Carboxylated Cellulose Nanofiber Performance as Binder for Flexible Lithium-Ion Batteries. ACS Appl. Mater. Interfaces 2017, 9, 37712-37720.

(9) Leijonmarck, S.; Cornell, A.; Lindbergh, G.; Wågberg, L. Flexible Nano-Paper-Based Positive Electrodes for Li-Ion Batteries-Preparation Process and Properties. Nano Energy 2013, 2, 794-800.

(10) Leijonmarck, S.; Cornell, A.; Lindbergh, G.; Wågberg, L. Single-Paper Flexible Li-Ion Battery Cells through a Paper-Making Process Based on Nano-Fibrillated Cellulose. J. Mater. Chem. A 2013, 1, 4671-4677.

(11) Pan, R.; Wang, Z.; Sun, R.; Lindh, J.; Edström, K.; Strømme, M.; Nyholm, L. Thickness Difference Induced Pore Structure Variations in Cellulosic Separators for Lithium-Ion Batteries. Cellulose 2017, 24, 2903-2911.

(12) Chun, S.-J.; Choi, E.-S.; Lee, E.-H.; Kim, J. H.; Lee, S.-Y.; Lee, S.-Y. Eco-Friendly Cellulose Nanofiber Paper-Derived Separator Membranes Featuring Tunable Nanoporous Network Channels for Lithium-Ion Batteries. J. Mater. Chem. 2012, 22, 16618-16626.

(13) Sheng, J.; Tong, S.; He, Z.; Yang, R. Recent Developments of Cellulose Materials for Lithium-Ion Battery Separators. Cellulose 2017, 24, 4103-4122.

(14) Pan, R.; Cheung, O.; Wang, Z.; Tammela, P.; Huo, J.; Lindh, J.; Edström, K.; Strømme, M.; Nyholm, L. Mesoporous Cladophora Cellulose Separators for Lithium-Ion Batteries. J. Power Sources 2016, 321, 185-192.

(15) Kim, J. H.; Kim, J. H.; Choi, E. S.; Yu, H. K.; Kim, J. H.; Wu, Q.; Chun, S. J.; Lee, S. Y.; Lee, S. Y. Colloidal Silica NanoparticleAssisted Structural Control of Cellulose Nanofiber Paper Separators for Lithium-Ion Batteries. J. Power Sources 2013, 242, 533-540.

(16) Kim, J.-H.; Gu, M.; Lee, D. H.; Kim, J.-H.; Oh, Y.-S.; Min, S. H.; Kim, B.-S.; Lee, S.-Y. Functionalized Nanocellulose-Integrated Heterolayered Nanomats toward Smart Battery Separators. Nano Lett. 2016, 16, 5533-5541.

(17) Zhang, J.; Yue, L.; Kong, Q.; Liu, Z.; Zhou, X.; Zhang, C.; Xu, Q.; Zhang, B.; Ding, G.; Qin, Bi.; Duan, Y.; Wang, Q.; Yao, J.; Cui, G.; Chen, L. Sustainable, Heat-Resistant and Flame-Retardant CelluloseBased Composite Separator for High-Performance Lithium Ion Battery. Sci. Rep. 2015, 4, 3935.

(18) Zhang, J.; Liu, Z.; Kong, Q.; Zhang, C.; Pang, S.; Yue, L.; Wang, X.; Yao, J.; Cui, G. Renewable and Superior Thermal-Resistant Cellulose-Based Composite Nonwoven as Lithium-Ion Battery Separator. ACS Appl. Mater. Interfaces 2013, 5, 128-134.

(19) Xu, Q.; Kong, Q.; Liu, Z.; Wang, X.; Liu, R.; Zhang, J.; Yue, L.; Duan, Y.; Cui, G. Cellulose/Polysulfonamide Composite Membrane 
as a High Performance Lithium-Ion Battery Separator. ACS Sustainable Chem. Eng. 2014, 2, 194-199.

(20) Xu, Q.; Kong, Q.; Liu, Z.; Zhang, J.; Wang, X.; Liu, R.; Yue, Li.; Cui, G. Polydopamine-Coated Cellulose Microfibrillated Membrane as High Performance Lithium-Ion Battery Separator. RSC Adv. 2014, 4, 7845-7850.

(21) Ji, L.; Lin, Z.; Alcoutlabi, M.; Zhang, X. Recent Developments in Nanostructured Anode Materials for Rechargeable Lithium-Ion Batteries. Energy Environ. Sci. 2011, 4, 2682-2699.

(22) Wang, Z.; Pan, R.; Ruan, C.; Edström, K.; Strømme, M.; Nyholm, L. Redox-Active Separators for Lithium-Ion Batteries. Adv. Sci. 2018, 5, 1700663.

(23) Jabbour, L.; Bongiovanni, R.; Chaussy, D.; Gerbaldi, C.; Beneventi, D. Cellulose-Based Li-Ion Batteries: A Review. Cellulose 2013, 20, 1523-1545.

(24) Xu, D.; Wang, B.; Wang, Q.; Gu, S.; Li, W.; Jin, J.; Chen, C.; Wen, Z. High-Strength Internal Cross-Linking Bacterial CelluloseNetwork- Based Gel Polymer Electrolyte for Dendrite-Suppressing and High- Rate Lithium Batteries. ACS Appl. Mater. Interfaces 2018, 10, 17809-17819.

(25) Xiao, S.; Wang, F.; Yang, Y.; Chang, Z.; Wu, Y. An Environmentally Friendly and Economic Membrane Based on Cellulose as a Gel Polymer Electrolyte for Lithium Ion Batteries. RSC Adv. 2014, 4, 76-81.

(26) Isogai, A.; Saito, T.; Fukuzumi, H. TEMPO-Oxidized Cellulose Nanofibers. Nanoscale 2011, 3, 71-85.

(27) Zhu, Y. S.; Xiao, S. Y.; Li, M. X.; Chang, Z.; Wang, F. X.; Gao, J.; Wu, Y. P. Natural Macromolecule Based Carboxymethyl Cellulose as a Gel Polymer Electrolyte with Adjustable Porosity for Lithium Ion Batteries. J. Power Sources 2015, 288, 368-375.

(28) Lin, C.; Zhang, H.; Song, Y.-Z.; Zhang, Y.; Yuan, J.-J.; Zhu, B.K. Carboxylated Polyimide Separator with Excellent Lithium Ion Transport Properties for High-Power Densities Lithium-Ion Battery. J. Mater. Chem. A 2018, 6, 991-998.

(29) Zahn, R.; Lagadec, M. F.; Hess, M.; Wood, V. Improving Ionic Conductivity and Lithium-Ion Transference Number in Lithium-Ion Battery Separators. ACS Appl. Mater. Interfaces 2016, 8, 3263732642.

(30) Choi, S. H.; Kang, H. J.; Ryu, E. N.; Lee, K. P. Electrochemical Properties of Polyolefin Nonwoven Fabric Modified with Carboxylic Acid Group for Battery Separator. Radiat. Phys. Chem. 2001, 60, 495502.

(31) Han, M.; Kim, D. W.; Kim, Y. C. Charged Polymer-Coated Separators by Atmospheric Plasma-Induced Grafting for Lithium-Ion Batteries. ACS Appl. Mater. Interfaces 2016, 8, 26073-26081.

(32) Liu, C.; Shao, Z.; Wang, J.; Lu, C.; Wang, Z. Eco-Friendly Polyvinyl Alcohol/Cellulose Nanofiber- $\mathrm{Li}^{+}$Composite Separator for High-Performance Lithium-Ion Batteries. RSC Adv. 2016, 6, 9791297920.

(33) Kim, M.; Byun, J.; Chung, S.; Lee, S.; Kang, J.; Park, J. (Samsung Electronics Co., LTD., KR) Method of Producing Cellulose Nonwoven Fabric, Cellulose Nonwoven Fabric Produced Thereby, and Secondary Ion Battery Including the Same. US Patent 0,331,093, November, 16, 2017.

(34) Kang, J.; Kim, H.; Yun, J.; Chung, S.; Cho, K. (Samsung Electronics CO., LTD., KR). Separator Including Microbial Cellulose, Method of Producing the Separator, and Use of the Separator. US Patent 0,351,874, December 1, 2016.

(35) Lu, H.; Behm, M.; Leijonmarck, S.; Lindbergh, G.; Cornell, A. Flexible Paper Electrodes for Li-Ion Batteries Using Low Amount of TEMPO-Oxidized Cellulose Nanofibrils as Binder. ACS Appl. Mater. Interfaces 2016, 8, 18097-18106.

(36) Saito, T.; Kimura, S.; Nishiyama, Y.; Isogai, A. Cellulose Nanofibers Prepared by TEMPO-Mediated Oxidation of Native Cellulose. Biomacromolecules 2007, 8, 2485-2491.

(37) Katz, S.; Beatson, R. P.; M, S. A. The Determination of Strong and Weak Acidic Groups in Sulphite Pulps. Sven. Papperstidning 1984, $87,48-53$.
(38) Ding, G.; Qin, B.; Liu, Z.; Zhang, J.; Zhang, B.; Hu, P.; Zhang, C.; Xu, G.; Yao, J.; Cui, G. A Polyborate Coated Cellulose Composite Separator for High Performance Lithium Ion Batteries. J. Electrochem. Soc. 2015, 162, A834-A838.

(39) Barrett, E. P.; Joyner, L. G.; Halenda, P. P. The Determination of Pore Volume and Area Distributions in Porous Substances. I. Computations from Nitrogen Isotherms. J. Am. Chem. Soc. 1951, 73, 373-380.

(40) Schneider, C. A.; Rasband, W. S.; Eliceiri, K. W. NIH Image to ImageJ: 25 Years of Image Analysis. Nat. Methods 2012, 9, 671-675.

(41) Liang, H.-q.; Wan, L.-s.; Xu, Z.-k. Poly(Vinylidene Fluoride) Separators with Dual-Asymmetric Structure for High-Performance Lithium Ion Batteries. Chin. J. Polym. Sci. 2016, 34, 1423-1435.

(42) Lekha, P.; Mtibe, A.; Motaung, T. E.; Andrew, J. E.; Gibril, M.; Sitholè, B. B. Effect of Mechanical Treatment on Properties of Cellulose Nanofibrils Produced from Bleached Hardwood and Softwood Pulps. Maderas, Cienc. Tecnol. 2016, 18, 457-466.

(43) Benhamou, K.; Dufresne, A.; Magnin, A.; Mortha, G.; Kaddami, H. Control of Size and Viscoelastic Properties of Nanofibrillated Cellulose from Palm Tree by Varying the TEMPO-Mediated Oxidation Time. Carbohydr. Polym. 2014, 99, 74-83.

(44) Willgert, M.; Leijonmarck, S.; Lindbergh, G.; Malmström, E.; Johansson, M. Cellulose Nanofibril Reinforced Composite Electrolytes for Lithium Ion Battery Applications. J. Mater. Chem. A 2014, 2, 13556-13564.

(45) Sato, Y.; Kusaka, Y.; Kobayashi, M. Charging and Aggregation Behavior of Cellulose Nanofiber in Aqueous Solution. Langmuir 2017, 33, 12660-12669.

(46) Finegan, D. P.; Cooper, S. J.; Tjaden, B.; Taiwo, O. O.; Gelb, J.; Hinds, G.; Brett, D. J. L.; Shearing, P. R. Characterising the Structural Properties of Polymer Separators for Lithium-Ion Batteries in 3D Using Phase Contrast X-Ray Microscopy. J. Power Sources 2016, 333, 184-192.

(47) Sehaqui, H.; Zhou, Q.; Ikkala, O.; Berglund, L. A. Strong and Tough Cellulose Nanopaper with High Specific Surface Area and Porosity. Biomacromolecules 2011, 12, 3638-3644.

(48) Aurbach, D. Review of Selected Electrode-Solution Interactions Which Determine the Performance of $\mathrm{Li}$ and $\mathrm{Li}$ Ion Batteries. J. Power Sources 2000, 89, 206-218.

(49) An, S. J.; Li, J.; Daniel, C.; Mohanty, D.; Nagpure, S.; Wood, D. L. The State of Understanding of the Lithium-Ion-Battery Graphite Solid Electrolyte Interphase (SEI) and Its Relationship to Formation Cycling. Carbon 2016, 105, 52-76.

(50) Metzger, M.; Strehle, B.; Solchenbach, S.; Gasteiger, H. A. Hydrolysis of Ethylene Carbonate with Water and Hydroxide under Battery Operating Conditions. J. Electrochem. Soc. 2016, 163, A1219A1225.

(51) O’Neill, H.; Pingali, S. V.; Petridis, L.; He, J.; Mamontov, E.; Hong, L.; Urban, V.; Evans, B.; Langan, P.; Smith, J. C.; Davison, B. J. Dynamics of Water Bound to Crystalline Cellulose. Sci. Rep. 2017, 7, 11840 .

(52) Berthold, J.; Desbrières, J.; Rinaudo, M.; Salmén, L. Types of Adsorbed Water in Relation to the Ionic Groups and Their CounterIons for Some Cellulose Derivatives. Polymer 1994, 35, 5729-5736.

(53) Sacui, I. A.; Nieuwendaal, R. C.; Burnett, D. J.; Stranick, S. J.; Jorfi, M.; Weder, C.; Foster, E. J.; Olsson, R. T.; Gilman, J. W. Comparison of the Properties of Cellulose Nanocrystals and Cellulose Nanofibrils Isolated from Bacteria, Tunicate, and Wood Processed Using Acid, Enzymatic, Mechanical, and Oxidative Methods. ACS Appl. Mater. Interfaces 2014, 6, 6127-6138.

(54) Peng, Y.; Gardner, D. J.; Han, Y.; Cai, Z.; Tshabalala, M. A. Influence of Drying Method on the Surface Energy of Cellulose Nanofibrils Determined by Inverse Gas Chromatography. J. Colloid Interface Sci. 2013, 405, 85-95.

(55) Guo, X.; Wu, Y.; Xie, X. Water Vapor Sorption Properties of Cellulose Nanocrystals and Nanofibers Using Dynamic Vapor Sorption Apparatus. Sci. Rep. 2017, 7, 14207. 
(56) Nakamura, K.; Hatakeyama, T.; Hatakeyama, H. Studies on Heat Capacity of Cellulose and Lignin by Differential Scanning Calorimetry. Text. Res. J. 1981, 51, 607-613.

(57) Berthold, J.; Olsson, R. J. O.; Salmén, L. Water Sorption to Hydroxyl and Carboxylic Acid Groups in Carboxymethylcellulose (CMC) Studied with NIR-Spectroscopy. Cellulose 1998, 5, 281-298.

(58) Xie, L.; Zhao, L.; Wan, J.; Shao, Z.; Wang, F.; Lv, S. The Electrochemical Performance of Carboxymethyl Cellulose Lithium as a Binding Material for Anthraquinone Cathodes in Lithium Batteries. J. Electrochem. Soc. 2012, 159, A499-A505. 